\title{
EDUCAÇÃO PARA A DEMOCRACIA EM TEMPOS DITATORIAIS: Análise da Reforma da Carta da OEA (Protocolo de Buenos Aires, 1967) em seu Contexto
}

\author{
Beatriz Mendes Niyama \\ Autora correspondente. Pontifícia Universidade Católica de Campinas - PUC-Campinas. Rua Professor Doutor Euryclides de Jesus \\ Zerbini, 1.516. Parque Rural Fazenda Santa Cândida. Campinas/SP, Brasil. CEP 13087-571. http://lattes.cnpq.br/1123005044112013. \\ https://orcid.org/0000-0001-7883-5735. biamendees91@gmail.com \\ Guilherme Perez Cabral \\ Pontifícia Universidade Católica de Campinas - PUC-Campinas. Campinas/SP, Brasil.
}

RESUMO

O artigo tem como objetivo analisar o processo de construção normativa, no cenário de guerra fria, do Protocolo de Buenos Aires (1967) - que reforma a Carta da Organização dos Estados Americanos (OEA) - particularmente a introdução da noção de educação para democracia. Partindo da relação entre governos autoritários e a Organização Interamericana, a pesquisa concentrou-se na atuação da ditadura civil-militar brasileira neste processo. Foi adotado método histórico-documental, a partir de fontes primárias, como relatórios, atas de reuniões e correspondências da Organização e dos representantes dos Estados, identificados a partir da sistematização dos arquivos físicos do Centro de Pesquisa e Documentação de História Contemporânea do Brasil (FGV-RJ), complementados pela revisão bibliográfica crítica da matéria. Os resultados atingidos permitem a conclusão de que a conexão entre educação e democracia, inserida na Carta da OEA por meio da atuação de governos autoritários, atende à perspectiva econômica liberal, constituindo, em última análise, uma educação para o capitalismo liberal, na luta anticomunista. Conclui-se que a inserção da democracia como objetivo educacional representa, do ponto de vista político-pedagógico, uma promessa vazia.

Palavras-chave: Educação; democracia; sistema interamericano.

EDUCATION FOR DEMOCRACY IN DICTATORIAL TIMES:

ANALYSIS OF THE OAS CHARTER REFORM (BUENOS AIRES PROTOCOL, 1967) IN ITS CONTEXT ABSTRACT

The article analyzes the process of normative construction, in the Cold War scenario, of the Buenos Aires Protocol (1967) - which reformed the Charter of the Organization of American States (OAS) - particularly the introduction of the notion of education for democracy. From the liberal economic perspective, prevalent in the inter-American Organization, under the influence of the United States, it focuses on the important function of the Brazilian Civil-Military Dictatorship in this period. It was adopted a documentary - historical method based on reports, meeting minutes and correspondence of the Organization and the representatives of the States - complemented by a critical bibliographic review of the subject. The results reached to allow the conclusion that the connection between education and democracy, inserted in the OAS Charter, meets the liberal economic perspective, constituting, ultimately, an education for liberal capitalism in the anti-communist struggle.

Keywords: Education; democracy; inter-american system.

Recebido em: 6/6/2020

Aceito em: $10 / 2 / 2021$ 


\section{INTRODUÇÃO}

O vínculo entre o sistema educacional e o fortalecimento da democracia é sistematicamente afirmado nas fontes documentais da Organização dos Estados Americanos (OEA). Esta conexão pode ser observada no Protocolo Adicional à Convenção Americana sobre Direitos Humanos em Matéria de Direitos Econômicos, Sociais e Culturais de 1988 ("Protocolo de San Salvador"), que, no artigo 13 , parágrafo $2^{\circ}$, dispõe: "a educação deve tornar todas as pessoas capazes de participar efetivamente de uma sociedade democrática e pluralista".

Faz isso de forma muito mais enfática do que os tratados que compõem o sistema global, nos quais a orientação à democracia não aparece, expressamente, como fim educacional. A lacuna não impediu, é verdade, que, notadamente com a "onda de democratização", ao final do século 20 - com a disseminação de governos democráticos, ao menos no nível formal, em países de todos os continentes - o fim democrático passasse a ser deduzido dos textos convencionais, na interpretação da Organização das Nações Unidas e da Organização das Nações Unidas para a Educação, a Ciência e a Cultura (UNESCO). ${ }^{1}$

De qualquer forma, a conexão entre educação e democracia, no âmbito do sistema interamericano, começa antes, contraditoriamente, num momento hostil à convivência democrática na América Latina. Fez-se, ademais, em vista de fins pouco atentos à sua efetiva concretização. O contexto de sua emergência e os fins para os quais foram arquitetados demandam, por isso, atenção. O direito internacional dos direitos humanos, dentro de uma perspectiva crítica, não pode olvidá-los.

A Organização dos Estados Americanos (OEA) emerge de processo de integração regional e liberalização comercial, capitaneado pelos Estados Unidos. Remonta a 1889, com a criação da União Internacional das Repúblicas Americanas, mais tarde, União Pan-Americana. Em 1948, na IX Conferência Internacional Americana (Bogotá), é adotado seu tratado constitutivo (Carta da OEA), oficializando a transformação da União Pan-Americana na nova Organização (SCOTT, 1994, p. 19).

Sua constituição vincula-se, em grande medida, à política externa dos Estados Unidos, afirmada inicialmente, ainda no século 19, na Doutrina Monroe. Por meio dela, buscavam afastar intervenções "externas" no continente americano, reivindicando sua superioridade em relação à região (KOSKENNIEMI, 2016, p. 601).

Atrelada ao projeto imperialista estadunidense, a Organização consolida-se em torno dos interesses deste país (BUENO; OLIVEIRA, 1997, p. 251). A utilização da OEA como plataforma de legitimação de determinadas pautas foi essencial para a construção, no período da guerra fria (1947 - 1991), da luta "anticomunista" no continente americano.

\footnotetext{
A título de exemplo, a ONU, em seu Programa Mundial em matéria de educação em direitos humanos, direcionou-a também à "participação efetiva de todas as pessoas em uma sociedade livre e democrática na qual impere o Estado de Direito" (ORGANIZAÇÃ̃O DAS NAÇÕES UNIDAS (ONU). Plano de Ação Programa Mundial para Educação em Direitos Humanos: Primeira Fase. 2005-2007. Nova York/Genebra, 2006. Nesse mesmo sentido, os documentos elaborados pela Unesco, ainda na década de 90: "Plano de Ação Mundial em favor da Educação para os Direitos Humanos e a Democracia" (Montreal, 1993) e "Declaração e Plano de Ação Integrado sobre a Educação para a Paz, os Direitos Humanos e a Democracia" (Paris, 1995).
} 
O combate ao comunismo atrelado à manutenção do modelo capitalista liberal ocasionou o apoio da Organização às invasões armadas na República Dominicana em 1965 (HERZ, 2012, p. 321) e a suspensão de Cuba, como membro do sistema interamericano, com a justificativa de que a adoção de um governo marxista-leninista seria incompatível com os princípios democráticos da Organização (OEA, 1962, p. 3).

O comprometimento da Organização com as pautas estadunidenses no período da guerra fria foi reconhecido e questionado, em diferentes níveis, pelos demais países-membros. Castro (1962), um crítico radical à Organização, a resumiu a um mero "Ministério da Colônia dos EUA". O governo Jango comparou a luta anticomunista da Organização a uma "caça às bruxas" (LIMA, 1963, p. 175).

A iniciativa anticomunista aparece, precipuamente, em termos de esforços para a consolidação da democracia e o desenvolvimento econômico e social. É bem verdade, a utilização da noção de "democracia" para a preservação de interesses assumidos como "continentais" no embate com o "inimigo" comum não se tratava de uma novidade. Ainda no período da União Pan-Americana, especificamente no cenário da Segunda Guerra, aparece ligado à "segurança continental", servindo a "defesa da democracia" como expediente para impedir a troca comercial entre países americanos e os países do Eixo (GAMBINI, 1977, p. 17).

A defesa da democracia, agora, confunde-se com a consolidação e manutenção das instituições econômicas liberais e a promoção da sociedade capitalista. $O$ "inimigo" é o comunismo. Conecta-se, pois, a uma "concepção liberal de Estado como protetor de uma sociedade centrada na economia" (HABERMAS, 1995, p. 43). Para tanto vai admitir, inclusive, a convivência e a manutenção de relações com governos autoritários.

É nesse cenário de conivência com o autoritarismo que se identifica a participação ativa da ditadura civil-militar brasileira na construção normativa da Organização, inclusive como viabilizadora da primeira reforma do tratado constitutivo da OEA pelo Protocolo de Buenos Aires (1967).

Entre as diversas modificações promovidas pelo Protocolo de Buenos Aires destaca-se a referência ao direito à educação e a afirmação de sua importância para a consolidação das instituições democráticas. Textualmente, é conferida importância primordial ao "desenvolvimento da educação (...) como condição da democracia", redação alterada, mais uma vez, pelo Protocolo de Washington (1992), quando o artigo 47 adquire seu formato atual:

Os Estados membros darão primordial importância, dentro dos seus planos de desenvolvimento, ao estímulo da educação, da ciência, da tecnologia e da cultura, orientadas no sentido do melhoramento integral da pessoa humana e como fundamento da democracia, da justiça social e do progresso.

De forma a contextualizar o Protocolo de Buenos Aires em seu período histórico, o presente artigo tem como objetivo analisar o processo de inclusão na Carta da aludida relação próxima entre educação e democracia, com enfoque na estratégia utilizada pelo governo militar brasileiro, e instaurada com o auxílio de atores de destaque na política externa, como Antônio Francisco Azeredo da Silveira e Juracy Montenegro Magalhães.

Diante deste cenário, e considerando a importância de investigar as "condições que levam à produção e manifestação" (SHAFFER; GINSBURG, 2015, p. 195) do direito internacional, 
a investigação optou por se valer do método histórico de base empírica documental (YEUNG, 2017, p. 15), com foco em fontes primárias como relatórios, atas de reuniões e correspondências da Organização e representantes dos Estados².

A adoção da pesquisa empírica, somada à análise crítica da matéria, a partir dos aportes da produção científica do Direito, em diálogo transdisciplinar com outras áreas do conhecimento, resultou no rastreamento do processo histórico da estruturação do Protocolo de Buenos Aires, e sua conexão com as perspectivas e interesses do governo militar brasileiro. Permitiu, destarte, a análise do "objeto de estudo em sua complexidade, em suas múltiplas características e relações" (IGREJA, 2017, p. 14).

O artigo dedica-se, primeiro, ao cenário brasileiro de instauração de regime ditatorial civil-militar e assimilação do discurso econômico liberal. Destacando a atuação do Instituto de Pesquisas e Estudos Sociais, organização empresarial com importante atuação no golpe, debruça-se especificamente sobre a relação então traçada entre educação e democracia (1). Na sequência analisa o protagonismo da ditadura brasileira na II Conferência Interamericana Extraordinária, pautado em discurso de defesa dos direitos humanos e da democracia (2). A aprovação do texto da reforma, incluindo a menção genérica à importância da educação para a experiência democrática, é o objeto do terceiro tópico (3). Daí, podemos enfim analisar, em conclusão, a afirmação da educação para a democracia, no sistema OEA, como educação para o capitalismo liberal. Isso a ponto de, cínica e contraditoriamente, poder conviver com governos autoritários, desde que alinhados ao modelo econômico estadunidense.

Os resultados parciais da presente pesquisa foram apresentados, no formato de Comunicação Oral, no IX Encontro de Pesquisa Empírica em Direito (Eped), promovido pela Rede de Pesquisa Empírica em Direito (Reed) e ocorrido em 2019, na Universidade Federal de São Paulo.

\section{A EDUCAÇÃO PARA A DEMOCRACIA COMO LUTA ANTICOMUNISTA NO BRASIL: A ATUAÇÃO DO INSTITUTO DE PESQUISAS E ESTUDOS SOCIAIS}

Instaurado em 1ㅇ de abril de 1964, o governo ditatorial brasileiro inicia a construção de projeto educacional de teor econômico liberal, com a parceria entre militares e o setor empresarial (VIEIRA; VIEIRA, 2018, p. 1.041), o qual se consolidará em reformas instituídas em documentos legais como a Lei no 5.5.40/1968 ("reforma universitária") e a Lei no 5.692/1971

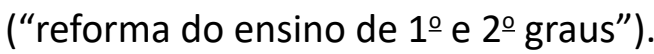

Entre os órgãos que influenciaram e protagonizaram tais empreendimentos, importa ressaltar o Instituto de Pesquisas e Estudos Sociais (Ipes), organização de empresários constituída em 1961 com o escopo de "defender a liberdade pessoal e da empresa, ameaçada pelo plano de socialização dormente no seio do governo João Goulart, através de um aperfeiçoamento de consciência cívica e democrática do povo" (LAMARÃO, 2020, p. 1).

O Ipes teve importante participação no Golpe de Estado, por meio de intensa propaganda de oposição ao então presidente da República e de combate ao comunismo (RAMíREZ,

\footnotetext{
2 A documentação que embasou a presente pesquisa encontra-se disponível no arquivo físico do Centro de Pesquisa e Documentação de História Contemporânea do Brasil (FGV-RJ).
} 
2010, p. 76) - valendo-se, para tanto, de cursos, conferências, livros, panfletos e artigos. Após a consolidação do regime ditatorial, encerrou suas atividades em 1971.

A defesa da democracia liberal - mesmo que cínica e contraditoriamente, por governos ditatoriais - como antecipado na introdução, tinha respaldo no sistema interamericano. Nesse sentido, na Carta de Punta del Este (1961), a OEA propugnara o aperfeiçoamento e fortalecimento das instituições democráticas, a promoção do desenvolvimento econômico e social, tudo de forma concomitante à obstrução da "expansão de ideias políticas que contrariam os princípios interamericanos".

A Carta incorpora a "Aliança para o Progresso", programa de assistência ao desenvolvimento social e econômico do continente, capitaneado pelos EUA. Previa que "a preservação e o fortalecimento das instituições livres e democráticas nas repúblicas americanas exigem, como condição essencial, a pronta e acelerada execução de um inédito esforço para promover seu desenvolvimento econômico e social" (OEA, 1962, p. 12).

A luta anticomunista envolvia, no plano militar, a atuação da Comissão Especial de Segurança, órgão ligado ao Tratado Interamericano de Assistência Recíproca (Tiar), que na definição de Hermes Lima, ministro de Relações Exteriores no governo Jango, funcionava "sem qualquer consulta prévia a determinado país, investigando sobre atividades comunistas, como mandatária da OEA, dentro de suas fronteiras" (LIMA, 1963, p. 181).

Se a Organização, no entanto, era vista com resguardo pelo governo brasileiro pré-golpe, o mesmo não ocorreu durante o governo militar-civil, em que a entidade foi considerada, pelo setor militar, mais representativa do que a própria ONU para "assegurar a paz e o entendimento aspirados pelo mundo inteiro" (MAGALHÃES, 2018, p. 247).

Assim, a perspectiva democrática, alinhada aos interesses estadunidenses, e consolidada pelo sistema interamericano, restringia-se a uma concepção liberal-burguesa, pouco atenta à efetiva participação popular, que foi rapidamente assimilada pelos governos militares do continente americano. Ressoando esse discurso, hegemônico na organização regional, o Ipes apresentara como plataforma de luta anticomunista a defesa da democracia liberal, com o lema: "não há democracia sem a empresa privada" (SOUZA, 1978, p. 22). Consolidado como braço intelectual da ditadura, a influência do Ipes no campo educacional se institucionaliza em uma série de reformas promovidas pelo governo militar brasileiro (SOUZA, 1978; BRISO NETO, 2008; CUNHA; GÓES, 1995).

Do conjunto delas destacamos aqui a proposta de reforma educacional, em concomitância e/ou parceria a projetos de organizações como a Agência dos Estados Unidos para o Desenvolvimento Nacional (Usaid) e o Banco Mundial (NOGUEIRA, 1999, p. 39).

Em linhas gerais, a política educacional moldada no Ipes visa a atender uma dupla missão, "evitar futuros movimentos de contestação através da educação das massas, mas sem abrir mão da formação de quadros para as elites, ou seja, que entenda o processo educativo para além da questão técnica" (CARVALHO, 2007, p. 378).

Baseava-se, ademais, na divisão entre escola da massa - educação primária para capacitação das atividades práticas e Ensino Médio focado em capacitação profissional - e ensino universitário, construído para formar "líderes" das elites (SAVIANI, 2008, p. 34). 
Fundamentado no "binômio: capitalismo e democracia" (BARROS, 1993, p. 35), o direito à educação, especificamente o ensino primário, teria como objetivo duplo a capacitação profissional e a democracia, com grande ênfase no primeiro.

Esta dupla orientação da educação, capital e democracia, aparece no documento "Delineamento Geral de um Plano de Educação para a Democracia no Brasil", formulado pelo Ipes em razão do evento "Simpósio sobre a Reforma da Educação" (1964). ${ }^{3}$ O documento defende a necessidade de uma educação voltada para o desenvolvimento econômico para fortalecer a democracia.

O caráter profissionalizante, centrado no mercado, se depreende do próprio preâmbulo do documento que define "É imperativo nacional a solução definitiva e imediata do problema do analfabetismo, ampliando-se, paralelamente, em grande escala, a oportunidade de educação profissional técnica" (IPES, 1964, p. 1).

A educação para a democracia é vinculada - e limitada - à educação para o trabalho, reconhecendo-se que "As pré-condições de uma democracia industrial e tecnificada ainda não se completaram sobre nós" (IPES, 1964, p. 2).

Sendo, assim, uma perspectiva democrática condicionada a uma estrutura capitalista e liberal de economia, o documento parte do pressuposto de que "nossos problemas democráticos resultam, em grande parte, da deseducação do nosso povo" (IPES, 1964, p. 3).

Ao discutir temáticas propriamente pedagógicas, como currículo e métodos de ensino, o documento defende um ensino primário de "[...] aculturação do educando, por meio de um processo elaborado a partir da gestalt que socialize a criança desde o seu ambiente até a inclusão de elementos universais" (IPES, 1964, p. 10). E o ensino secundário de "[...] facilitação de uma formação para atividades do campo econômico" (p. 10).

Conclui-se que as reformas educacionais devem reforçar na população a compreensão de que a "verdadeira função" da educação "deve ser a instrumental, que quando subestimada causa desorientação política, social e econômica" (p. 20).

A educação de caráter profissionalizante seria o suficiente para a capacitação democrática, oferecendo "[...] orientação política, social e econômica, de modo a assegurar atitudes coletivas favoráveis ao progresso ou desenvolvimento das instituições democráticas, à evolução social e ao aumento da produção econômica" (IPES, 1964, p. 23).

Eis a perspectiva educacional que, impondo-se a partir do golpe, fundamenta a ação do governo brasileiro que levará à proposta de reforma da Carta da OEA por meio do Protocolo de Buenos Aires (1967).

\footnotetext{
Evento ocorreu 2 meses após a decretação da prisão de Paulo Freire. Um dos tópicos dos eventos foi a discussão de como atingir o sucesso do método "Freire" sem a aplicação de um ensino político: "Cita o êxito relativo do 'método Paulo Freire', mas deixa claro que o método pode ser aproveitado desde que seu conteúdo esteja dentro dos objetivos da democracia brasileira" (SOUZA, Maria Inêz S. de. Estudo sobre o pensamento educacional das elites no Brasil. 1978. 259 f. Dissertação (Mestrado) - FGV, Curso de Educação, Rio de Janeiro, 1978).
} 


\section{A ATUAÇÃO BRASILEIRA NA II CONFERÊNCIA INTERAMERICANA EXTRAORDINÁRIA: A CONSTRUÇÃO DA NARRATIVA DITATORIAL SOBRE DIREITOS HUMANOS E DEMOCRACIA}

No cenário supramencionado, o governo civil-militar brasileiro pôde seguir, em sua política externa, com a pauta da defesa da democracia, assim como dos direitos humanos.

Tal política externa envolveu, entre seus passos, a realização, no país, em 1965, da II Conferência Interamericana Extraordinária, evento que, na definição de Vasco da Cunha, ministro de Relações Exteriores do Brasil (1965), foi "sonhado e organizado pelo governo brasileiro".

A posição "progressista" na política externa, sem dúvida, contrastava com um cenário interno em que, além das violações de direitos individuais, já vigoravam os Atos Institucionais no 1 - estabelecendo eleições indiretas e possibilidade de cassação de direitos políticos - e no 2, prevendo fim dos partidos políticos e possibilidade de declaração de estado de sítio sem autorização do Congresso.

A proposição do encontro corresponde à medida adotada pelo governo militar brasileiro, em momento de preocupação em relação à ineficácia da Carta de Punta del Este, "apenas uma resolução de um conselho assessor ${ }^{4}$ ao conselho da OEA, não tendo portanto força contratual o suficiente", assim como à "falta de dinamismo e limitada capacidade de ação" da organização (SILVEIRA, 1965a, p. 3).

Entre os objetivos sugeridos ao evento: o "Desenvolvimento econômico e social no continente", a "Proteção de direitos humanos e projeto de convenção específica" e o "Fortalecimento da democracia representativa" (SILVEIRA, 1965b, p. 4).

Apesar de a reforma da Carta da OEA não figurar diretamente na agenda proposta, Azeredo da Silveira, chefe da delegação brasileira na OEA, detalha que "sem uma reforma substancial de alguns dispositivos da Carta de Bogotá, não será possível lograr os objetivos coligados pelos Estados membros". Daí sua referência à convocação, desde logo, de uma Conferência para posteriormente, "de acordo com o artigo 111 da Carta, proceder com a sua revisão" (SILVEIRA, 1965c, p. 8).

Convocada a II Conferência Extraordinária, o governo envia aos países membros, por meio da Circular no 5.660 de 23/4/1965, projetos que o Brasil pretendia apresentar, incluindo projeto de convenção sobre direitos humanos. ${ }^{5}$

Reafirma, nesse documento, compromisso acordado previamente de criação de uma "Corte Interamericana para proteger os direitos humanos", salientando os "importantes pas-

\footnotetext{
4 A Carta de Punta del Este foi um documento criado a partir da VIII Reunião de Consulta dos Ministros das Relações Exteriores, mas por não se tratar de um tratado ou de uma diretiva da Assembleia Geral, foi considerado sem força vinculante. Fonte: ROCHA, Dário do Carmo. A carta de Punta del Este: as idéias positivistas nas reformas educacionais e no plano de segurança nacional orquestradas na década de 60. In: SEMINÁRIO NACIONAL ESTADO E POLÍTICAS SOCIAIS DO BRASIL, 2. ., 2005. Cascavel. Anais [...]. Cascavel: Unioeste, 2005.

5 O governo também apresentou um projeto de reforma da Carta da OEA, um projeto de assistência econômica recíproca e uma proposta de constituição de um conselho interamericano da paz. Fonte: SILVEIRA, Antônio Francisco Azeredo da. [Circular no 5660]. 23 de abril de 1965b. Rio de Janeiro [para] Missões diplomáticas de países membros da OEA. 3f. II Conferência Extraordinária.
} 
sos (que) foram dados no sentido de assegurar o respeito aos direitos humanos, tanto no âmbito internacional, como no âmbito interno dos países" (SILVEIRA, 1965b, p. 5).

Indica, ainda, a necessidade de aumentar as atribuições da Comissão Interamericana de Direitos Humanos, a qual, afirma, "vem desenvolvendo um trabalho constante e dedicado com o objetivo de estipular a consciência dos direitos humanos" (SILVEIRA, 1965b, p. 6). Finalmente, a referência à necessidade de constituição, na II Conferência, de Comissão Especial para a elaboração de projeto da Convenção de Direitos Humanos.

Tal esforço discursivo em favor dos direitos humanos aplica-se, também, à defesa da democracia representativa, valendo mencionar, nessa linha, as "Orientações para a Delegação Brasileira na II Conferência" (16/11/1965) expedida pelo chefe do executivo brasileiro, na iminência do encontro:

[...] a posição brasileira deverá ser prudente e reservada. No entanto, não deve se deixar passar qualquer insinuação de delegados estrangeiros relativamente a situações internas brasileiras. A Comissão poderia fazer um discurso sobre o funcionamento dos 3 poderes no Brasil, bem como liberdade de expressão e o novo estatuto dos partidos.

É notável, nesse cenário, a ausência de questionamentos da OEA em relação ao cenário político brasileiro. O mesmo por parte do governo norte-americano: "o Departamento de Estado norte-americano negou-se a comentar o Ato Institucional no 2 (...) afirmando, entretanto, considerar que a situação criada não impedirá, de maneira alguma, a realização da conferência interamericana" (SILVEIRA, 1965d, p. 1).

Diametralmente oposta à admissão da participação da ditadura brasileira nas discussões sobre democracia, é a ação da Organização em relação à República Dominicana, no mesmo momento histórico (1965-1966), diante do movimento "constitucionalista", que objetivava o retorno do presidente Juan Bosch, acusado de "comunismo" e deposto em golpe militar. Lá, os esforços empreendidos pelos "constitucionalistas" de restabelecimento da democracia foram classificados como atos "contra a segurança continental", o que levou à intervenção da OEA, inclusive estabelecendo força militar para lutar em conjunto com as tropas estadunidenses. ${ }^{6}$

Neste cenário, de conivência aos governos ditatoriais, alinhados ao capitalismo liberal, em detrimento a luta "anticomunista", a II Conferência, iniciada em 17/11/1965, conduziu os debates sobre os temas enumerados em sua agenda e produziu dois documentos:

i) Ata do Rio de Janeiro, em que consta a convocação de III Conferência Interamericana Extraordinária, e a constituição de Comissão Especial, "composto por representantes de cada um dos Estados membros, (para) a preparação de um anteprojeto de proposta sobre alterações à Carta da Organização" (OEA, 1965a, p. 4).

\footnotetext{
Na X Reunião de Ministros de Relações exteriores, foi estabelecida força interamericana, composta pelos exércitos da Argentina, Brasil, Colômbia, Guatemala e Panamá, para combater, em conjunto com as tropas americanas, o movimento constitucionalista. A força interamericana ficaria em território dominicano entre 1965 e junho de 1966 e auxiliaria a eleição de Joaquín Balaguer, que ficaria no poder da República dominicana pelos próximos 22 anos. Fonte: OEA. Ata da Reunião X. Reunião de Consulta dos Ministros das Relações Exteriores. Washington. 1/5/1965 a 06/03/1970; MARINHO, IImar Penha. [Telegrama] 6 de junho de 1965, Washington. [para] ministro das Relações Exteriores. Brasília. 2 f. Situação Política na República Dominicana.
} 


\section{Humanos e \\ Democracia}

ii) Ata Econômica Social do Rio de Janeiro. Estipula que:

[...] instituições democráticas são os melhores meios para satisfazer as aspirações do homem em obter emprego e justiça social, terra e habitação, educação e saúde, e nenhum sistema pode garantir o verdadeiro progresso a menos que afirme a dignidade do indivíduo (OEA, 1965b, p. 7).

Aborda, também, a relação entre o desenvolvimento econômico e social e a segurança coletiva, oficializando a união dos Estados-membros em "esforço comum para permitir que seus povos alcancem a maior justiça social e um progresso econômico mais rápido e equilibrado, essencial à segurança do Hemisfério" (OEA, 1965b, p. 7).

Por fim, adotando a proposta defendida pelo Brasil, é aprovada Declaração a fim de aumentar as competências da $\mathrm{CIDH}$, que, assim, torna-se responsável por "supervisionar a observância dos direitos humanos referidos na Declaração Americana dos Direitos e Deveres do Homem" (OEA, 1965b, p. 5).

\section{DA COMISSÃO ESPECIAL DO PANAMÁ À III CONFERÊNCIA INTERAMERICANA EXTRAORDINÁRIA: A AFIRMAÇÃO GENÉRICA DA EDUCAÇÃO PARA DEMOCRACIA}

A Comissão Especial, reunida no Panamá, funcionou, entre 25/2/1966 e 2/3/1966, como fórum para a elaboração do texto do protocolo que originaria a reforma, nos termos da Ata do Rio de Janeiro. Das propostas debatidas, abrangendo inclusive alterações na estrutura organizacional da OEA, debateremos, em virtude do recorte temático do presente artigo, somente o capítulo relativo aos direitos sociais.

A delegação brasileira possuía a orientação de impedir o "retrocesso ou diluição" da ata econômica social do Rio de Janeiro e de estipular versão de projeto de reforma para "recolher na Carta os elementos permanentes que dão efeito propriamente político na ata econômica social" (MAGALHÃES, 1966a, p. 3).

No projeto de protocolo apresentado pelo Brasil destaca-se a inclusão de um capítulo dedicado exclusivamente à educação, cultura e ciência, o que não estava previsto no primeiro projeto proposto pelo país na II Conferência.

O novo capítulo foi ao final aprovado. Para Azeredo da Silveira: "todos os conceitos fundamentais integrantes no projeto brasileiro foram atingidos sem perda substancial, ainda que não haja identidade de forma entre os dois documentos" (SILVEIRA, 1966, p. 6): 


\section{Democracia}

\begin{tabular}{|c|c|c|}
\hline $\begin{array}{l}\text { Texto original da Carta (Versão } \\
\text { 1948) }\end{array}$ & $\begin{array}{l}\text { Projeto brasileiro de reforma a Carta } \\
\text { (Apresentado em 25/2/1966) }\end{array}$ & $\begin{array}{l}\text { Versão final do projeto elaborado } \\
\text { pela Comissão Especial do Panamá } \\
(2 / 3 / 1966)\end{array}$ \\
\hline Normas Culturais & $\begin{array}{l}\text { Normas sobre educação, a ciência e a } \\
\text { cultura }\end{array}$ & $\begin{array}{l}\text { Normas sobre educação, a ciência } \\
\text { e a cultura }\end{array}$ \\
\hline $\begin{array}{l}\text { Artigo 30: Os Estados mem- } \\
\text { bros acordam em favorecer, de } \\
\text { acordo com os seus preceitos } \\
\text { constitucionais e seus recursos } \\
\text { materiais, o exercício do direito } \\
\text { à educação, sobre as seguintes } \\
\text { bases: } \\
\text { a) O Ensino primário será } \\
\text { obrigatório e, quando ministrado } \\
\text { pela Estado, será gratuito. } \\
\text { b O acesso aos estudos superi- } \\
\text { ores será reconhecido a todos, } \\
\text { sem distinção de raça, naciona- } \\
\text { lidade, sexo, idioma, credo ou } \\
\text { condição social. }\end{array}$ & $\begin{array}{l}\text { Artigo 1- Os Estados membros reconhe- } \\
\text { cem que o desenvolvimento integral da } \\
\text { pessoa humana é a finalidade primor- } \\
\text { dial da educação a qual constitui, além } \\
\text { disso, um fator preponderante para } \\
\text { o progresso científico e para o desen- } \\
\text { volvimento econômico e social. }\end{array}$ & $\begin{array}{l}\text { Artigo 1- Os Estados membros } \\
\text { darão primordial importância, nos } \\
\text { seus planos de desenvolvimento, } \\
\text { ao desenvolvimento da educação, } \\
\text { da ciência e da cultura, orientado } \\
\text { no sentido do melhoramento in- } \\
\text { tegral da pessoa humana e como } \\
\text { condição da democracia, da justiça } \\
\text { social e do progresso. }\end{array}$ \\
\hline $\begin{array}{l}\text { Artigo 31- Os Estados membros } \\
\text { se comprometem a facilitar, den- } \\
\text { tro do respeito devido à person- } \\
\text { alidade de cada um deles, o livre } \\
\text { intercâmbio cultural, através de } \\
\text { todos os meios de expressão. }\end{array}$ & $\begin{array}{l}\text { Artigo 2- Os Estados membros cooper- } \\
\text { arão entre si a fim de atender às suas } \\
\text { necessidades no tocante à educação, } \\
\text { promover a pesquisa científica e impul- } \\
\text { sionar o progresso tecnológico. Con- } \\
\text { sideram-se individual e solidariamente } \\
\text { comprometidos a preservar e enriquec- } \\
\text { er o patrimônio cultural dos povos } \\
\text { americanos. }\end{array}$ & Sem modificação \\
\hline & $\begin{array}{l}\text { Artigo 3- Os Estados membros em- } \\
\text { preenderão os maiores esforços para } \\
\text { assegurar, de acordo com suas normas } \\
\text { constitucionais, o exercício efetivo do } \\
\text { direito à educação, observados os se- } \\
\text { guintes princípios } \\
\text { a) O ensino primário, obrigatório para a } \\
\text { população em idade escolar, será igual- } \\
\text { mente estendido a todas as pessoas a } \\
\text { quem possa aproveitar. Quando minis- } \\
\text { trado pelo Estado, será gratuito; } \\
\text { b) O ensino médio deverá ser estendi- } \\
\text { do progressivamente com critério de } \\
\text { promoção social, à maior parte pos- } \\
\text { sível da população. Será diversificado } \\
\text { de maneira que, sem prejuízo da for- } \\
\text { mação geral dos educandos, atenda às } \\
\text { necessidades do desenvolvimento de } \\
\text { cada país; } \\
\text { c) A educação de grau superior será } \\
\text { acessível a todos, independentemente } \\
\text { de condição social e sem prejuízo da } \\
\text { manutenção de alto nível de ensino e } \\
\text { do enriquecimento do conhecimento } \\
\text { humano em seus diferentes campos. }\end{array}$ & $\begin{array}{l}\text { Artigo 3- Sem modificação (caput). } \\
\text { a) O ensino primário será } \\
\text { obrigatório para a população em } \\
\text { idade escolar. Quando ministrado } \\
\text { pelo Estado, será gratuito. } \\
\text { b) Sem modificação. } \\
\text { c) Na medida em que for com- } \\
\text { patível com a necessidade de } \\
\text { manter alto nível de ensino e de } \\
\text { enriquecer o conhecimento hu- } \\
\text { mano em seus diferentes campos, } \\
\text { a educação de grau superior será } \\
\text { acessível a todos, sem distinção de } \\
\text { condição social. }\end{array}$ \\
\hline
\end{tabular}




\section{Democracia}

\begin{tabular}{|l|l|l|}
\hline & $\begin{array}{l}\text { Artigo 4- Os Estados membros dispen- } \\
\text { sarão especial atenção à erradicação } \\
\text { do analfabetismo, fortalecerão os siste- } \\
\text { mas de educação de adultos e habil- } \\
\text { itação para o trabalho, assegurarão a } \\
\text { toda população o gozo dos bens da cul- } \\
\text { tura e promoverão o emprego de todos } \\
\text { os meios de divulgação para o cumpri- } \\
\text { mento de tais propósitos. }\end{array}$ & $\begin{array}{l}\text { Artigo 5- Os Estados membros promov- } \\
\text { erão o desenvolvimento da ciência e e } \\
\text { da tecnologia por meio de instituições } \\
\text { de pesquisa e de ensino, bem como de } \\
\text { programas extensivos de divulgação. }\end{array}$ \\
\hline & $\begin{array}{l}\text { Artigo 6- Os Estados meano } \\
\text { em promover, dentro do respeito devi- } \\
\text { do à personalidade de cada um deles, } \\
\text { o intercâmbio cultural como meio de } \\
\text { eficaz para consolidar a compreensão } \\
\text { interamericana; e reconhecem que os } \\
\text { programas de integração regional de- } \\
\text { vem ser fortalecidos mediante estreita } \\
\text { vinculação no setores da educação, da } \\
\text { ciência e da cultura. }\end{array}$ \\
\hline
\end{tabular}

Importa observar que a correlação entre educação e democracia não se fez presente na proposta inicialmente apresentada pelo Brasil. Nesta, na linha das discussões no âmbito do Ipes, além da referência ao desenvolvimento individual da pessoa, confere-se destaque, em sua perspectiva social, à ligação da educação à economia.

Nesse sentido, a previsão da educação como "um fator preponderante para o progresso científico e para o desenvolvimento econômico" (Artigo1ํ) e o compromisso dos Estados em dedicar especial atenção à "habilitação para o trabalho" (Artigo 4ㅇ).

A correlação é inserida, em negociações posteriores, por meio de modificação ao primeiro artigo do capítulo:

Os Estados membros darão primordial importância, nos seus planos de desenvolvimento, ao desenvolvimento da educação, da ciência e da cultura, orientado no sentido do meIhoramento integral da pessoa humana e como condição da democracia, da justiça social e do progresso.

Introduzido na Carta da OEA em 1966 por meio do Protocolo de Buenos Aires, o dispositivo sofrerá, ainda, alteração em 1992, por meio do Protocolo de Washington. Só então adquire sua redação atual.

Quanto às justificativas oficiais para a inclusão do termo "democracia", remetem à afirmação dos princípios e objetivos a reger a educação: "princípios interamericanos [...] a democracia, a justiça social e o progresso, dentro do espírito do preâmbulo e dos princípios da carta" (OEA, 1966, p. 16). 
Menciona-se também a "Declaração Interamericana sobre Educação, Ciência e Cultura", formulada pelo Conselho Cultural Interamericano" em janeiro de 1966 . Fundamentando a posição brasileira - "a estrutura do projeto brasileiro constitui um todo harmonioso e sintético (...) dentro dos princípios gerais estabelecidos na Declaração Interamericana sobre Educação, Ciência e Cultura" (MAGALHÃES, 1966b, p. 114) - dispõe expressamente sobre a relação entre educação e democracia: "a educação tem na América o dever iniludível de promover e fortalecer os princípios da democracia representativa e o respeito aos direitos fundamentais do homem".

De todo modo, no contraditório, senão cínico, cenário de defesa de instituições democráticas (liberais), o que sobressai no texto é a vagueza do conteúdo normativo de uma educação para a democracia. Fala-se em "desenvolvimento da educação (...) como condição da democracia". Só isso. Fórmulas genéricas e vagas cujos limites acabaram submetidos aos interesses liberais, prevalecentes na OEA e, assim, poderem ser afirmadas e defendidas por governos autoritários.

A ausência de delimitação de meios para atingir o objetivo educacional do fortalecimento da democracia é expressa no próprio relatório da delegação brasileira, ao explicar que "nas normas do capítulo (educação, cultura e ciência), buscou-se evitar a adjetivação e o detalhe (...) sem entrar nos pormenores mais próprios de um estatuto" (MAGALHÃES, 1966b, p. 118).

Após a conclusão dos trabalhos da Comissão Especial do Panamá, e antes da III Conferência Extraordinária em Buenos Aires, a Argentina sofre, em junho de 1966, golpe militar, liderado pelo general Juan Carlos Onganía (SORBILLE, 2008, p. 84).

Abraçando a mudança no governo argentino, a posição brasileira foi pela continuidade da Conferência, naquele país, "porque o governo argentino assegura as condições necessárias e porque aos outros países do continente não cabe criar dificuldades adicionais para uma República irmã, recém-egressa duma grave crise" (MAGALHÃES, 1966b, p. 121).

E, mais uma vez, a OEA permaneceu conivente com o governo ditatorial. A III Conferência inicia-se em 15/2/1967 e, ocorrendo sem questionamentos quanto à derrubada do governante democraticamente eleito, aprova, em seu encerramento (26/2/1967), a versão final do Protocolo de Buenos Aires.

Com a versão de projeto consolidada na Comissão Especial do Panamá, a Conferência apenas formaliza a aprovação do projeto, que se converteu no Protocolo de Reforma. Com isto, o capítulo "Normas sobre educação, ciência e cultura", proposto pela delegação brasileira, foi oficialmente integrado à Carta da OEA.

\section{EDUCAÇÃO PARA A DEMOCRACIA COMO EDUCAÇÃO PARA O CAPITALISMO}

Em suma, por meio do Protocolo de Buenos Aires, a Carta da OEA passa a reconhecer expressamente a relação entre educação e democracia. Estabelece, destarte, como dever ser no ordenamento jurídico interamericano, a educação para a democracia.

\footnotetext{
Segundo a Carta da OEA, o Conselho Cultural Interamericano "tem como objetivo promover relações amistosas e entendimento mútuo entre os povos americanos, para fortalecer os sentimentos pacíficos que têm caracterizado a evolução americana, através do estímulo do intercâmbio educacional, científico e cultural" (Artigo 73 da Carta na versão original de 1948), alterado pelo Protocolo de Buenos Aires para Conselho Interamericano de Educação, Ciência e Cultura.
} 
O contexto, entretanto, é hostil a uma experiência democrática. Aprovada por meio do Protocolo de Buenos Aires, logo após a Argentina sofrer golpe militar, a reforma à Carta da OEA emerge de proposta da Comissão Especial (Panamá) - convocada em Conferência realizada no Brasil, já sob o regime militar - contando com a participação bastante ativa do governo ditatorial brasileiro.

O dispositivo convencional então aprovado, vimos, é vago e impreciso. Num texto que buscou "evitar a adjetivação e o detalhe" (MAGALHÃES, 1966b, p. 118) inexistiam, ademais, instrumentos ou procedimentos para integrar seu sentido normativo. É propositalmente construído como conceito normativo genérico, permitindo a discricionariedade e ampla liberdade de seus intérpretes.

Dessa forma, pode ser harmonizado e delimitado semanticamente de acordo com a atuação e os propósitos da organização interamericana, sob o comando dos Estados Unidos, no contexto da guerra fria. Na linha de um cínico "vocabulário humanista", fica subordinado aos interesses imperialistas capitalistas liberais sobre o continente, os quais, em última análise, determinavam "o que estas palavras poderiam significar, quais políticas apoiariam e quais políticas condenariam” (KOSKENNIEMI, 2016, p. 599).

O termo "democrático" torna-se, no continente americano, um adjetivo que se refere ao sistema capitalista liberal, servindo para justificar quaisquer medidas à sua promoção, mesmo que contrárias ao disposto nas fontes documentais da Organização.

Propugna-se o aperfeiçoamento das instituições democráticas, ao lado de governos autoritários, faz-se do combate à expansão de ideias políticas que contrariem os princípios interamericanos, a luta anticomunista.

Com tal conteúdo, a afirmação da educação como condição para a democracia harmoniza-se aos interesses e perspectivas educacionais assumidas por governos ditatoriais do período. Harmoniza-se, pois, com os interesses e perspectivas educacionais do governo brasileiro pós-golpe de 1964.

Permite ao governo ditatorial, em seu alinhamento ao "Delineamento Geral de um Plano de Educação para a Democracia no Brasil", elaborado pelo Ipes e, com tal abordagem, a participação ativa na reforma da Carta da OEA, fazendo a defesa cínica da "democracia, a justiça social e o progresso econômico, dentro do espírito da Carta" (MAGALHÃES, 1966b, p. 116).

No compromisso com o liberalismo, os documentos formulados pelo Ipes e o projeto brasileiro de reforma da Carta da OEA aproximam-se na redução da educação aos objetivos de "propriedade, democracia e prosperidade". ${ }^{8}$

Do ponto de vista político-pedagógico - no sentido da delimitação do conteúdo democrático, que constitui o fim, e dos métodos e instrumentos democráticos que definem as bases e os meios para realizá-lo - a educação para a democracia implicou uma "promessa vazia". Serviu de recurso discursivo para a promoção do liberalismo econômico. Eis o con-

\footnotetext{
8 O Ipes declarava expressamente que seus objetivos eram "propriedade, democracia e prosperidade". Ante a aproximação entre o governo ditatorial brasileiro e o Ipes, o artigo considerou que a proposta formulada pelos delegados brasileiros seguiu os mesmos objetivos da organização. Fonte: SOUZA, Maria Inêz S. de. Estudo sobre o pensamento educacional das elites no Brasil. 1978. 259 f. Dissertação (Mestrado) - FGV, Curso de Educação, Rio de Janeiro, 1978.
} 
teúdo hermenêutico, no período, das ideias de promoção e fortalecimento da democracia, desenvolvimento econômico e social e a proteção aos direitos humanos. São expressões que, no contexto sociopolítico da guerra fria, significaram promoção do capitalismo liberal e combate ao comunismo.

Dessa forma, o discurso democrático pôde conviver com regimes ditatoriais militares, atuantes na organização regional e por ela respaldados, desde que alinhados ao capitalismo liberal. Combinado aos demais dispositivos do capítulo aprovado pelo Protocolo de Buenos Aires, a fórmula educação como condição da democracia não é mais do que educação orientada ao desenvolvimento individual e à habilitação para trabalho, na (e somente na) economia de mercado.

Dentro de um ambiente que impedia as experiências profundamente participativas, a concepção de cidadania no sistema interamericano se resumia aos pilares liberais de "individualismo e o direito à propriedade privada" (PRADO; SOARES; COLOMBO, 2007, p. 118). ${ }^{9}$

No final das contas, a ideia de democracia não subsiste sequer como democracia burguesa, liberal, permitindo, para a manutenção do liberalismo econômico, que percam espaço e sejam mitigadas, senão negadas, as instituições democráticas.

\section{CONCLUSÃO}

No cenário de redemocratização, a "onda de democratização", do final do século 20, e o fim da guerra fria, o conceito normativo de educação para a democracia, inicialmente previsto no Protocolo de Buenos Aires, é expandido pelo Protocolo de San Salvador (1988). A educação, não se questiona, "deve tornar todas as pessoas capazes de participar efetivamente de uma sociedade democrática e pluralista".

Não se pode ignorar, nesse contexto, o papel do sistema interamericano, seja pela atuação da OEA, em especial por meio da Comissão Interamericana de Direitos Humanos, seja pela atuação da Corte Interamericana, na promoção dos direitos humanos e de valores democráticos no continente (DULITSKY, 2011, p. 56).

Isso não autoriza, entretanto, a leitura ingênua, imersa em compromissos morais universalistas e sentimentos humanitários (KOSKENNIEMI, 2016, p. 607), dos textos convencionais e direitos que compõem o Direito Internacional dos Direitos Humanos, desconsiderando sua gênese profundamente contraditória e mesmo cínica.

A visão mais "realista" da história do Direito Internacional dos Direitos Humanos, como a adotada no presente artigo, somente é possível com a pesquisa empírica. Os documentos originais - que migraram dos arquivos pessoais de atores do período para centros históricos dão voz ao "não dito" das fontes documentais, e permitem a descoberta de quais (e de quem) interesses se oficializaram no texto final.

Com isso, falar em educação para a democracia, no sistema interamericano, exige a permanente atenção em relação aos seus efetivos destinatários e interessados, pretéritos, atuais

A utilização de organizações internacionais como forma de consolidar a ideia de democracia liberal foi cunhada de "Internacionalismo liberal econômico" ou "Wilsonismo", em detrimento da atuação de Woodrow Wilson, presidente dos EUA, na criação da Liga das Nações (LACERDA, 2013). 
e futuros. Reconhecer que o conceito de educação para a democracia é uma herança do período da guerra fria, interligado a uma visão liberal - que abre mão, se necessário, das instituições democráticas - torna-se parte fundamental do caminho da ressignificação dos direitos humanos e do desenvolvimento democrático como objetivo educacional.

\section{REFERÊNCIAS}

BARROS, Ricardo Paes de. Pelo fim das décadas perdidas: educação e desenvolvimento sustentado no Brasil. In: HENRIQUES, Ricardo (org.). Desigualdade e pobreza no Brasil. Rio de Janeiro: Instituto de Pesquisa Econômica Aplicada, 2000.

BARROS, E. C. A. C. Estado militar e educação no Brasil (1964-1985). Revista Educação em Questão, v. 5, n. 2, p. 174-176, 15 dez. 1993. Disponível em: https://www.periodicos.ufrn.br/educacaoemquestao/article/ view/11028http://bdtd.ibict.br/vufind/Record/CAMP_48cb2436234ad70f73c695f0951b841e. Acesso em: 6 jun. 2020.

BRASIL. Executivo. [Telegrama] 16 de novembro de 1965, Brasília [para] Delegação Brasileira na OEA, Rio de Janeiro. 3 f. Orientações para a Delegação Brasileira na II Conferência.

BRISO NETO, Joaquim Luiz Pereira. O conservadorismo em construção: o Instituto de Pesquisas e Estudos Sociais - IPES e as reformas financeiras da Ditadura Militar (1961-1966). 2008. 187 f. Dissertação (Mestrado em Desenvolvimento Econômico) - Programa de Pós-Graduação em Economia da Universidade Estadual de Campinas - Unicamp, Campinas 2008. Disponível em: http://bdtd.ibict.br/vufind/Record/CAMP_48cb2436234ad70f73c695f0951b841e. Acesso em: 6 jun. 2020.

BUENO, Elen de Paula; OLIVEIRA, Victor Arruda Pereira de. O Congresso do Panamá (1826): perspectivas políticas, teóricas e jurídicas nas relações internacionais. São Paulo: Papel Político, 2015. Disponível em: http://www. scielo.org.co/pdf/papel/v20n1/v20n1a09.pdfhttp://bdtd.ibict.br/vufind/Record/CAMP_48cb2436234ad70f73c695f0951b841e. Acesso em: 6 jun. 2020.

CASTRO, Fidel. II Declaração de Havana (1962). In: ALI, Tariq (org.). As Declarações de Havana. 1. ed. Rio de Janeiro: Zahar, 2009.

CAMPOS, R. Educação e desenvolvimento econômico. Rio de Janeiro: Apec, 1969.

CARVALHO, Celso. O simpósio "A educação que nos convém: o lpes e a ação político-ideológica da burguesia na década de 1960". EccoS Revista Científica, São Paulo, v. 9, n. 2, p. 369-385, 2007. Disponível em: https://www. researchgate.net/publication/26548981_O_simposio_A_educacao_que_nos_convem_o_Ipes_e_a_acao_politico-ideologica_da_burguesia_na_decada_de_1960. Acesso em: 6 jun. 2020.

CUNHA, Luiz Antônio; GÓES, Moacyr de. O golpe na educação. 2. ed. Rio de Janeiro: Jorge Zahar, 1995.

CUNHA, Luiz Antônio. O legado da ditadura para a Educação Brasileira. Revista Educação e Sociedade, Campinas, v. 35, n. 127, p. 357-377, 2014. Disponível em: https://www.scielo.br/pdf/es/v35n127/v35n127a02.pdf. Acesso em: 6 jun. 2020.

DOURADO, L. F. Gestão democrática da escola: movimentos, tensões e desafios. In: SILVA, A. M. M.; AGUIAR, M. A. S. (org.). Retrato da escola no Brasil. Brasília: CNTE, 2004. p. 59-74.

DULITZKY A. The inter-american human rights system fifty years later: time for changes. Quebec Journal of International Law, Quebec, 2011. Disponivel em: https://www.sqdi.org/images/volumes/HS_2011_Dulitzky.pdf. Acesso em: 15 set. 2019.

GAMBINI, Roberto. $O$ duplo jogo de Getúlio Vargas: influência americana e alemã no Estado Novo. São Paulo: Símbolo, 1977.

HABERMAS, Jürgen. Três modelos normativos de democracia. Lua Nova - Revista de Cultura e Política, São Paulo, v. 36, n. 1, p. 39-54, 1995. Disponível em: http://www.scielo.br/scielo.php?script=sci_abstract\&pi$\mathrm{d}=\mathrm{S} 0102-64451995000200003 \& \operatorname{lng}=e n \& n r m=i s o \& t \operatorname{lng}=$ t. Acesso em: 5 nov. 2019.

HERZ, Mônica. Carta da OEA (1948). In: MAGNOLI, Demétrio (Org.). História da paz. 2. ed. São Paulo: Contexto, 2012. p. 315-336.

IPES. Instituto de Pesquisas e Estudos Sociais. Delineamento geral de um plano de educação para a democracia no Brasil. Simpósio sobre a reforma da educação, 1964, 65 p. Arquivo Nacional.

IGREJA, Rebecca Lemos. O Direito como objeto de estudo empírico: o uso de métodos qualitativos no âmbito da pesquisa empírica em Direito. In: MACHADO, Maíra Rocha (org.). Pesquisar empiricamente o direito. São Paulo: Rede de Estudos Empíricos em Direito, 2017. 
KOSKENNIEMI, M. Carl Schmitt and International Law. In: MEIERHENRICH, J.; SIMONS, O (org.). The Oxford Handbook of Carl Schmitt. 2. ed. Oxford: Oxford University Press, 2016. p. 592-608.

LACERDA, Jan Marcel de Almeida Freitas. A Organização dos Estados Americanos (OEA) e a disseminação de ideias de democracia na américa latina. 2013. 192 f. Dissertação (Mestrado) - Universidade Estadual da Paraíba, Programa de Pós-Graduação em Relações Internacionais, João Pessoa, 2013. Disponível em: http://pos-graduacao.uepb.edu.br/ppgri/download/Jan-Marcel.pdfhttps://www.scielo.br/pdf/es/v35n127/v35n127a02.pdf. Acesso em: 6 jun. 2020.

LAMARÃO, S. Instituto de Pesquisas e Estudos Sociais. In: FGV/CPDOC. Temático. Disponível em: http://www.fgv.

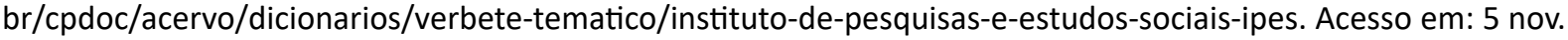
2020.

LIMA, Hermes. Política exterior do Brasil (1963). In: LIMA, Sérgio Eduardo Moreira; FARIAS, Rogério de Souza (org.). A palavra dos chanceleres na escola superior de guerra (1952-2012). 1. ed. Brasília: Funag, 2018. p. 173196. Disponível em: http://funag.gov.br/biblioteca/download/1255-a-palavra-dos-chanceleres-na-escola-superior-de-guerra-funag.pdf. Acesso em: 6 jun. 2020.

MAGALHÃES, Juracy Montenegro. A política exterior do Brasil (1966). In: LIMA, S. E. M.; FARIAS, R. de Souza (org.). A palavra dos chanceleres na escola superior de guerra (1952-2012). 1. ed. Brasília: Funag, 2018. p. 247272. Disponível em: http://funag.gov.br/biblioteca/download/1255-a-palavra-dos-chanceleres-na-escola-superior-de-guerra-funag.pdf. Acesso em: 6 jun. 2020.

MAGALHÃES, Juracy Montenegro. Relatório ao Senhor Ministro do Estado. Panamá, 1966b. 230 p.

MAGALHÃES, Juracy Montenegro. [Telegrama] 11 de fevereiro de 1966a. Brasília. [para] Delegação brasileira. Panamá. $8 \mathrm{f}$. Comissão especial do Panamá.

MARINHO, Ilmar Penha. [Telegrama] 6 de junho de 1965, Washington. [para] ministro das Relações Exteriores. Brasília. 2 f. Situação Política na República Dominicana.

NOGUEIRA, F. M. G. Ajuda externa para a educação brasileira - da Usaid ao Banco Mundial. Cascavel: Unioeste, 1999.

OEA. Ata da Reunião IV. Reunião de Consulta dos Ministros das Relações Exteriores. Washington. 26/3/1951 a 7/4/1951.

OEA. Ata da Reunião VIII. Reunião de consulta dos Ministros das Relações Exteriores. Punta del Este. 22 a 31 de Janeiro de 1962.

OEA. Ata da Reunião X. Reunião de Consulta dos Ministros das Relações Exteriores. Washington. 10/5/1965 a 6/3/1970.

OEA. Ata do Rio de Janeiro. II Conferência Interamericana Extraordinária. Rio de Janeiro. 17/11/1965 e 30/11/1965a.

OEA. Ata Econômica Social do Rio de Janeiro. II Conferência Interamericana Extraordinária. Rio de Janeiro. $17 / 11 / 1965$ e 30/11/1965b.

OEA. Ata final da Subcomissão II. Comissão Especial do Panamá. Panamá. 2/3/1966.

PRADO, M. L. C.; SOARES, G. P.; COLOMBO, S. Reflexões sobre a democracia na América Latina. São Paulo: Editora Senac, 2007.

RAMÍREZ, Hernán. Precursores del "consenso": itinerarios de algunas ideas en Brasil y Argentina, 19611991. Revista de Investigación, México, n. 34, 2010. Disponível em: https://www.redalyc.org/articulo. oa?id=279122162010. Acesso em: 5 nov. 2019.

ROCHA, Dário do Carmo. A carta de Punta del Este: as idéias positivistas nas reformas educacionais e no plano de segurança nacional orquestradas na década de 60. In: SEMINÁRIO NACIONAL ESTADO E POLÍTICAS SOCIAIS NO BRASIL, 2., 2005. Cascavel. Anais [...]. Unioeste, 2005. p. 1-12.

SAVIANI, Dermeval. História das idéias pedagógicas no Brasil. 2. ed. Campinas, SP: Autores Associados, 2008.

SHAFFER, G.; GINSBURG, T. A reviravolta empírica na doutrina do direito internacional. Revista de Estudos Empíricos em Direito, v. 2, n. 2, 30 jul. 2015. Disponível em: https://reedrevista.org/reed/article/view/80. Acesso em: 31 out. 2020.

SCOTT, James Brown. The Seventh International Conference of American States. The American Journal of International Law, Washington, v. 28, n. 2, 1994. Disponível em: https://www.jstor.org/stable/2190923?seq=1\#page_scan_tab_contents. Acesso em: 5 nov. 2019.

SILVEIRA, Antônio Francisco Azeredo da. [Telegrama]. 24 de fevereiro de 1965a. Rio de Janeiro [para] Delegação Brasileira, Washington. 5 f. II Conferência Interamericana Extraordinária. 
SILVEIRA, Antônio Francisco Azeredo da. [Circular no 5660]. 23 de abril de 1965b. Rio de Janeiro [para] Missões diplomáticas de países membros da OEA. 3 f. II Conferência Extraordinária.

SILVEIRA, Antônio Francisco Azeredo da. [Telegrama]. 26 de fevereiro de 1965c, Rio de Janeiro [para] Delegação Brasileira, Washington. 5 f. II Conferência Interamericana Extraordinária.

SILVEIRA, Antônio Francisco Azeredo da. [Telegrama]. 28 de outubro de 1965d. Washington [para] Secretaria de Estado das Relações Exteriores. $4 \mathrm{f}$. Jornais internacionais.

SILVEIRA, Antônio Francisco Azeredo da. [Telegrama no 88] 12 de março de 1966, Panamá [para] Secretaria de Estado de Relações Exteriores. Brasília. 10 f. CEP-OEA/962.C.

SORBILLE, Rosana Núbia. Três momentos para pensar uma história - Argentina 1966-1976. Revista de Pesquisa Histórica, Pernambuco, v. 1, n. 26, p. 83-100, nov. 2008.

SOUZA, Maria Inêz S. de. Estudo sobre o pensamento educacional das elites no Brasil. 1978. 259 f. Dissertação (Mestrado) - FGV, Curso de Educação, Rio de Janeiro, 1978. Disponível em: http://bibliotecadigital.fgv.br/dspace/bitstream/10438/9488/1/000012694.pdf. Acesso em: 6 jun. 2020.

VIEIRA, Beatriz de Moraes; VIEIRA, R. B. Intensidades, excepcionalidades e violência - as leis - modernizadoras - da educação no Brasil em 1968. Revista Direito e Práxis, v. 9, n. 2, 2018. Disponível em: https://www.e-publicacoes.uerj.br/index.php/revistaceaju/article/view/33903/24194. Acesso em: 5 nov. 2019.

YEUNG, Luciana. Jurimetria ou análise quantitativa de decisões judiciais. In: MACHADO, Maíra Rocha (org.). Pesquisar empiricamente o direito. São Paulo: Rede de Estudos Empíricos em Direito, 2017. 